Systematic Review

\title{
Life Experience of Human Immunodeficiency Virus (HIV) Sufferers: A Qualitative Systematic Review
}

\section{RTS Netisa Martawinarti, Putri Irwanti Sari and Vivi Meiti Berhimpong}

Faculty of Nursing, Universitas Airlangga, Surabaya, East Java, Indonesia

\begin{abstract}
Introduction: HIV is a chronic disease that continues to increase from year to year, with many symptoms or obstacles encountered by HIV sufferers when going about their day. The experience of HIV sufferers is important to know in order to find out what they have experienced for as long as they have had the disease. The objective of this qualitative systematic review is to describe the experiences of people living with HIV.
\end{abstract}

Methods: The method used was searching for journals using the predetermined keywords of 'experience', 'living with HIV' and 'coping' through the databases of Scopus, ProQuest, PubMed and Sage between 2014 and 2019.

Results: The study results showed that there was still discrimination against people with HIV. They also experienced health problems due to the effects of the therapy, unpreparedness in accepting their conditions and the prevention of transmission to their family members.

Conclusion: Understanding the role of uncertainty, stigma and resilience is important, since these factors may very well contribute to the patient's mental health.

\section{ARTICLE HISTORY}

Received: December 26, 2019

Accepted: December 31, 2019

\section{KEYWORDS}

Live experience; HIV; qualitative

\section{CONTACT}

RTS Netisa Martawinarti $\triangle$ netisamw@gmail.com $\equiv$ Faculty of Nursing, Universitas Airlangga, Surabaya, Indonesia

Cite this as: Martawinarti, R. N., Sari, P. I., \& Berhimpong, V. M. (2019). Life Experience of Human Immunodeficiency Virus (HIV) Sufferers: A Qualitative Systematic Review. Jurnal Ners, 14(3si), 418-421. doi:http://dx.doi.org/10.20473/in.v14i3(si).17069

\section{INTRODUCTION}

Virtually no country is immune to the HIV pandemic that has impacted on global health for more than 30 years (Alomepe, Buseh, Awasom \& Snethen, 2016). The human immunodeficiency virus is a major public health problem that has claimed the lives of more than 34 million people world-wide.1 In 2014 alone, .1 .2 million people died from HIV-related causes globally. At the end of 2014, 36.9 million people were reported to be living with HIV and 2 million people are estimated to be newly infected each year. In mid2015 , it was estimated that only $54 \%$ of all PLWH knew that they were infected (Norberg, Nelson, Holly, Jewell \& Salmond, 2017). Gaps in the health of the people who live with HIV based on racial, gender and social economic groups has survived for years. Understanding the social and economic situation in which people live, collectively known as social health determinants, helps to uncover the processes that interact to produce significant and unavoidable injustices in health outcomes (Caiola, Barroso, Docherty \& Univer, 2017) .

Since HIV was first identified more than 30 years ago, people living with the disease have experienced stigma from an array of people and institutions. This has continues to be a problem around the world. HIV stigma has a range of consequences, from emotional (e.g., verbal abuse, shunning) and through to physical (e.g., beatings, expulsion from the home) and financial (e.g., firing someone from a job). Stigma can also have a direct impact on the health of people living with HIV (PLWH) (Yvette, Alice, jennifer, Alphoncina \& Carol, 2016)

According to Dewey (Roth WM \& Jornet A, 2014), experience is the term most often used in education and it is recognized as a learning process. Experience shows transactions in a space and time that cannot be reduced. Five peer-facilitated focus groups were conducted involving 33 Aboriginal, Latino, Asian and African participants. The thematic analysis of their experiences revealed 4 dominant themes: the beginning of stigma, tensions related to disclosure, 
experience of service seeking and beyond the HIV stigma and discrimination. Persons living with HIV from Aboriginal and refugee communities continue to experience disproportionate rates of stigma and discrimination. Fear remains a prime obstacle influencing the sufferer's ability and willingness to access care in various settings (Donnelly et al, 2016).

\section{MATERIALS AND METHODS}

A systematic review was conducted by the researchers focused on qualitative methods. The researchers conducted semi-structured interviews, in-depth interviews and focus group discussions. The process was used to carry out systematic updates on several research articles published through electronic databases. The electronic databases used were Scopus, Sage Journal, ProQuest and PubMed. The keywords used for searching for the journals in English were "Experience", "HIV", "Coping" and "Qualitative research". The search results found in Sage were 62 journals, while Scopus had 99 journals, ProQuest had 143 journals and PubMed had 23 journals. The total number of journals found was 327 . Based on the inclusion criteria, namely 1) full text articles published in English, 2) research articles in the period 2014 - 2019, 3) qualitative research and 4) articles that use research content with HIV / AIDS sufferers, after the screening of the 327 articles, there were 15 articles that matched the expected criteria. The total number of respondents in this review was 450 people with HIV. The setting of this study was communities and clinics. For the 15 articles selected, the research was conducted in Africa, America, Canada, Asia, the Netherlands, Spain and Brazil. All of the articles analyzed based on the type of research were qualitative $(n=15)$. The most widely used research design was descriptive research $(n=6)$, followed by phenomenology $(n=3)$, and the rest were cohort studies, meta-synthesis and a general approach. This was found to be in connection with the year of publication. All of the samples in this study were HIV positive.

\section{RESULTS}

A total of 15 studies were included in the systematic review. The sample used in the study varied with the minimum sample of 8 and the maximum of 114 participants. The places where the research was conducted included Africa, America, Canada, Asia, the Netherlands, Spain and Brazil. Our search strategy was developed using a protocol guided by the PRISMA statement. The results of several research articles analyzed about the life experiences of HIV sufferers found there to be various life challenges experienced by PLWH including stigma, socio-economic issues, psychological and emotional difficulties and decreased physical health (Alomepe, Buseh, Awasom \& Snethen, 2016). According to research (Caiola, Barroso, Docherty \& Univer, 2017), HIV sufferers tend to experience physical changes caused by the HIV disease and the effects of ART, as well as loneliness

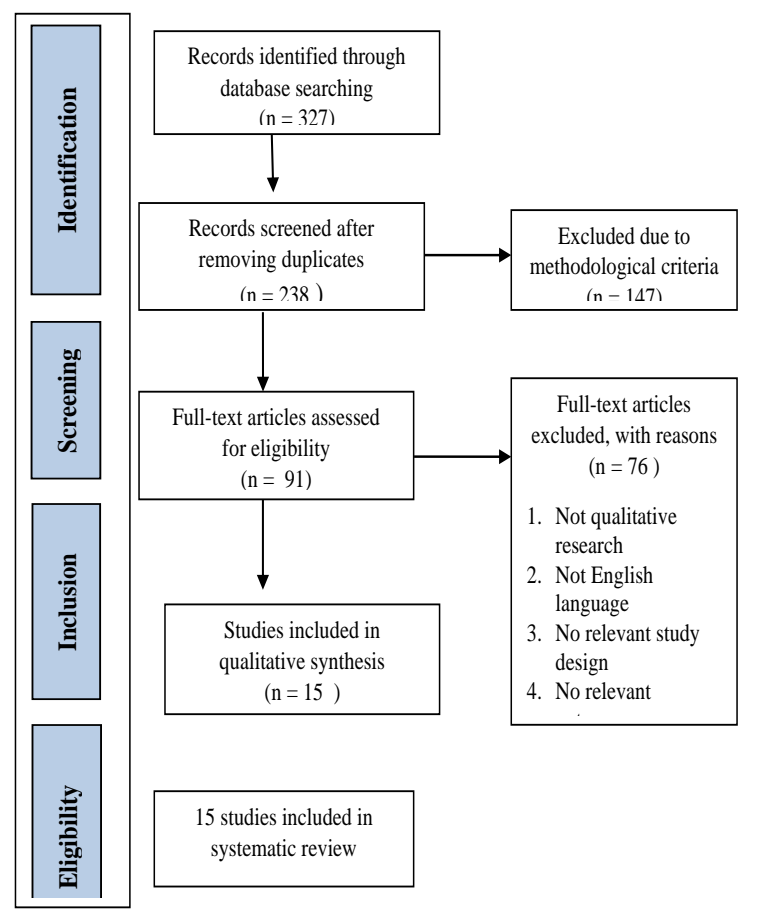

Figure 1: Flowchart of the study selection

problems. Other researchers indicate that the experience of HIV sufferers, especially woman, is more sad and anxious because they are afraid of infecting their family members. There are WLPH who are afraid to become pregnant because they can transmit $t$ to their children but there are also WLWH who want to get pregnant (Muze R \& Onsomu EO, 2017) (Fletcher, Ingram, Kerr, Buchberg, Richter, 2016). Experiencing unhappiness triggers feelings of despair, sadness and anger, which cause various effects such as low self-esteem, depression, anxiety, loneliness and sometimes the thought of suicide (Donnelly et al, 2016).The experience of HIV sufferers to reduce or eliminate sadness, fear and depression is often by getting closer to God. For HIV sufferers, to surrender to God can bring them peace (Tang K \& Chen W, 2018).

\section{DISCUSSION}

The 450 participants in this systematic review all had different life experiences since they were diagnosed with HIV. There were many changes that they had experienced while suffering from HIV and they had encountered various challenges while being PLWH. Unpleasant treatment starts includes discrimination, negative stigma, fear, difficulty getting access to health services, anger, uncertainty in life and anxiety when woman with HIV want to get pregnant. The feeling of fear of transmitting the disease to others is more likely to be experienced by women. Women who want to have children must hold back that feeling of fear of transmitting their HIV to their children. However, there were also participants in this systematic review that did not care much about the disease and who continued to have unprotected sex. 
In theory, the experience of a disease will cause various feelings and stress reactions, including frustration, difficulties, recovery, denial, shame, grieving and a struggle towards disease adaption (Nursalam, Kurniawati \& Misutarno, 2018). The theoretical explanation of the results found in this article were almost the same; HIV sufferers often experience low self-esteem, which makes them aloof and removed away from others for fear of transmitting the disease. However in this article, it was found that there were sufferers who experienced unpleasant actions because they were discriminated against by the people around them. This is due to a lack of knowledge within people about the HIV disease. There is still an assumption that HIV is easily transmitted and dangerous, resulting in a negative stigma towards HIV sufferers. The sufferers feeling sad, disappointed and angry is a form of ineffective coping because of the unpreparedness of the HIV sufferers to accept their illness.

The systematic review of the life experiences of HIV sufferers is needed to improve our understanding of the problems that are often faced by HIV sufferers, what factors can worsen the condition of HIV sufferers and what can affect the quality of life of people with HIV. This can help the medical personnel to find the right intervention or preventive measures to create the atmosphere needed by HIV sufferers so then their quality of life is better.

This systematic review only addresses the experience of HIV sufferers in general, not specifically in terms of the experience of pregnant woman with HIV or the experiences of HIV sufferers in the face of negative stigma and discrimination. This systematic review discusses experience in general and it does not seek out experience that consistently has the same background problem, so the results of the experiences found vary.

\section{CONCLUSION}

This systematic review shows the experience of HIV sufferers in living life as PLWH, how they defend themselves and continue to live life like other healthy people, how the HIV sufferers look for health services that meet their expectations and how they find peace when they are feeling sad, angry and depression. Not all HIV sufferers have good coping skills; many of the participants in this systematic review have ineffective coping mechanisms. A health worker or nurse ideally needs to systematically assess the aspects of suffering, coping, satisfaction and decision making of the HIV sufferers.

\section{REFERENCES}

Alomepe, J., Buseh, A. G., Awasom, C., \& Snethen, J. A. (2016). Life With HIV : Insights from HIV-infected Women in Cameroon, Central Africa. Journal of the
Association of Nurses in AIDS Care, 1-13. https://doi.org/10.1016/j.jana.2016.04.010

Brien, N. O., Greene, S., Carter, A., Lewis, J., Kaufman, E., Nicholson, V., ... Kaida, A. (2017). Envisioning Women-Centered HIV Care: Perspectives from Women Living with HIV in Canada. 1-10. https://doi.org/10.1016/j.whi.2017.08.001

Caiola, C., Barroso, J., Docherty, S. L., \& Univer-, D. (2017). An Inquiry Into How Social Determinants of Health Are Framed. 209-221. https://doi.org/10.1097/NNR.00000000000002 13

Donnelly, L., Baily, L., Jessani, A., Postnikoff, J., Kerston, P., \& Brondani, M. (2016). Stigma Experiences in Marginalized People Living with HIV Seeking Health Services and Resources in Canada. Journal of the Association of Nurses in AIDS Care. https://doi.org/10.1016/j.jana.2016.07.003

Fletcher, F., Ingram, L. A., Kerr, J., Buchberg, M., \& Richter, D. L. (2016). “" Out of All of this Mess , I Got a Blessing "': Perceptions and Experiences of Reproduction and Motherhood in African American Women Living With HIV. Journal of the Association of Nurses in AIDS Care, 1-11. https://doi.org/10.1016/j.jana.2015.12.003

Furlotte, C., \& Schwartz, K. (2017). Mental Health Experiences of Older Adults Living with HIV: Uncertainty, Stigma, and Approaches to Resilience *. 16. https://doi.org/10.1017/S0714980817000022

Imazu, Y., Ph, D., Matsuyama, N., Takebayashi, S., Mori, M., Ph, D., ... Ph, D. (2017). SC. International Journal of Nursing Sciences. https://doi.org/10.1016/j.ijnss.2017.02.004

James-borga, J. C., \& Frederickson, K. (2018). SC. Journal of the Association of Nurses in AIDS Care. https://doi.org/10.1016/j.jana.2018.01.003

Leyva-moral, J. M., Mart, R. N. F., \& V, B. M. (2019). The Experience of Growing Old While Living With HIV in Spain : A Phenomenological Study. 30(1), 111-118.

Leyva-moral, J. M., Piscoya-angeles, P. N., \& Edwards, J. E. (2017). The Experience of Pregnancy in Women Living With HIV: A Meta-Synthesis of Qualitative Evidence. Journal of the Association of Nurses in AIDS Care, 28(4), 587-602. https://doi.org/10.1016/j.jana.2017.04.002

Muze, R., \& Onsomu, E. O. (2017). Our Children , Our Hope : Voices of African American Mothers Living with HIV and Rearing Uninfected Children Our Children, Our Hope: Voices of African American Mothers. Journal of Community Health Nursing, 34(3), 160-168. https://doi.org/10.1080/07370016.2017.13407 70

Nation, A., Waters, C. M., \& Dawson-Rose, C. (2018). Experiences and Perceptions of Black Men Who Have Sex with Men About Acquiring HIV: A Qualitative Narrative Perspective. Journal of the Association of Nurses in AIDS Care, 29(5), 737-748. https://doi.org/10.1016/j.jana.2018.04.010

Norberg, A., Nelson, J., Holly, C., Jewell, S. T., \& 
Salmond, S. (2017). systematic review protocol. 2645-2650. https://doi.org/10.11124/JBISRIR2016-003278

Nursalam, K, N. D., Misutarno, \& S, F. K. (2018). Asuhan Keperawatan pada Pasien Terinfeksi HIV/AIDS (2nd ed.; P. P. Lestari \& T. Utami, eds.). Jakarta: Salemba Medika.

Peltzer, J. N., Ogawa, L., Tusher, S., Farnan, R., \& Gerkovich, M. M. (2016). AC. Journal of the Association of Nurses in AIDS Care. https://doi.org/10.1016/j.jana.2016.09.010

Proudfoot, D. (2017). AC Acknowledgements. Journal of the Association of Nurses in AIDS Care. https://doi.org/10.1016/j.jana.2017.10.003

Roth, W. M., \& Jornet, A. (2014). Toward a Theory of Experience. Science Education, 98(1), 106-126. https://doi.org/10.1002/sce.21085

Stutterheim, S. E., Brands, R., Baas, I., Lechner, L., Kok, G., \& Bos, A. E. R. (2017). SC. Journal of the Association of Nurses in AIDS Care. https://doi.org/10.1016/j.jana.2017.06.014

Tang, K., \& Chen, W. (2018). Original article HIV and religion in HIV-infected Asians and their families : A qualitative study. Applied Nursing Research, 44(June), 18-24. https://doi.org/10.1016/j.apnr.2018.09.003

Yvette P.Cuca, Alice Asher, jennifer Okonky, Alphoncina Kaihura, Carol Dawson, A. W. (2016). SC. Journal of the Association of Nurses in AIDS Care. https://doi.org/10.1016/j.jana.2016.09.001 